\section{BMJ Paediatrics Open}

\title{
Development of a core outcome set for clinical trials in childhood constipation: a study using a Delphi technique
}

Sophie Kuizenga-Wessel, ${ }^{1}$ Nina Francesca Steutel, ${ }^{1}$ Marc Alexander Benninga, ${ }^{1}$ Thierry Devreker, ${ }^{2}$ Elena Scarpato, ${ }^{3}$ Annamaria Staiano, ${ }^{3}$ Hania Szajewska, ${ }^{4}$ Yvan Vandenplas, ${ }^{2}$ Merit Monique Tabbers ${ }^{1}$

To cite: Kuizenga-Wessel S, Steutel NF, Benninga MA, et al. Development of a core outcome set for clinical trials in childhood constipation: a study using a Delphi technique. BMJ Paediatrics Open

2017;1:e000017. doi:10.1136/ bmjpo-2017-000017

- Prepublication history for this paper is available online. To view these files please visit the journal online (http://dx.doi.org/ 10.1136/bmjpo-2017-000017).

SK-W and NFS contributed equally.

Received 30 March 2017 Revised 14 June 2017 Accepted 14 June 2017

\section{(2) CrossMark}

${ }^{1}$ Department of Paediatric Gastroenterology and Nutrition, Emma Children's Hospital, Academic Medical Centre, Amsterdam, The Netherlands ${ }^{2}$ Department of Paediatrics, Free University of Brussels, Brussels, Belgium

${ }^{3}$ Department of Translational Medical Sciences - Section of Paediatrics, University of Naples Federico II, Naples, Italy ${ }^{4}$ Department of Paediatrics, The Medical University of Warsaw, Warsaw, Poland

Correspondence to Ms Nina Francesca Steutel; n.f. steutel@amc.uva.nl

\section{ABSTRACT}

Objective Patients, their parents and healthcare professionals ( $\mathrm{HCPs}$ ) have a different perception regarding the symptoms of functional constipation (FC). Consequently, a lack of agreement exists on definitions and outcomes used in therapeutic trials of FC. Therefore, our aim was to develop a core outcome set (COS) for FC for children aged $0-1$ year and $1-18$ years.

Design and setting Prospective study design: primary, secondary and tertiary care settings.

Methods This COS was developed using a Delphi technique. First, $\mathrm{HCPs}$, parents of children with $\mathrm{FC}$ and patients aged $\geq 12-18$ years were asked to list up to five outcomes they considered relevant in the treatment of FC. Outcomes mentioned by $>10 \%$ of participants were included in a shortlist. In the next phase, outcomes on this shortlist were rated and prioritised by HCPs, parents and patients. Outcomes with the highest scores were included in a draft COS. In a face-to-face expert meeting, the final COS was determined.

Results The first phase was completed by $109 \mathrm{HCPs}$, 165 parents and 50 children. Fifty HCPs, 80 parents and 50 children completed the subsequent phase. The response rate was between $63 \%$ and $100 \%$ in both steps. The final $\mathrm{COS}$ for all ages consisted of: defecation frequency, stool consistency, painful defecation, quality of life, side effects of treatment, faecal incontinence, abdominal pain and school attendance.

Conclusion The use of this COS for FC will decrease study heterogeneity and improve comparability of studies. Therefore, researchers are recommended to use this COS in future therapeutic trials on childhood FC.

\section{INTRODUCTION}

Functional constipation (FC) is a common problem with a worldwide prevalence of $0.7 \%-29.6 \% .^{1}$ Approximately $95 \%$ of children with constipation has FC, meaning that no organic or anatomic cause can be identified.

Standard definitions and criteria for FC exist but are rarely used in research and clinical practice. ${ }^{2}$ In 1999, the first diagnostic criteria for paediatric functional gastrointestinal disorders were published: the Rome
What is already known about this subject?

Heterogeneity in defining and measuring outcomes hampers comparison of efficacy trial results.

- A core outcome set (COS) for functional constipation (FC) can solve this issue.

\section{What this study hopes to add?}

- Involvement of healthcare professionals, parents and patients in the development of this COS for FC ensured that appropriate outcomes are measured.

- Final COS: defecation frequency, stool consistency, painful defecation, quality of life, side effects of treatment, faecal incontinence (if age appropriate), abdominal pain (if age appropriate) and school attendance (if age appropriate)

II criteria. Several studies showed, however, that these were too restrictive and were therefore modified into the Rome III criteria (2006) and recently into the Rome IV criteria. ${ }^{3-8}$

Differences in outcome definitions, measurement and reporting across clinical trials make it difficult to pool study results. Moreover, negative results are less likely to be reported, which can cause bias. ${ }^{9}$ These problems can be tackled by developing agreed standardised sets of outcomes: core outcome sets (COS). COS serve as a guide for what should be measured and reported, but measured outcomes do not need to be restricted to the COS. Researchers can examine additional outcomes that might be of interest to them. ${ }^{10-12}$

COS increase consensus about the efficacy of an intervention and can improve healthcare, but it needs to contain outcomes that really matter to stakeholders. It is important to involve healthcare professionals (HCPs), parents and patients with FC when developing a COS. Especially since the literature 


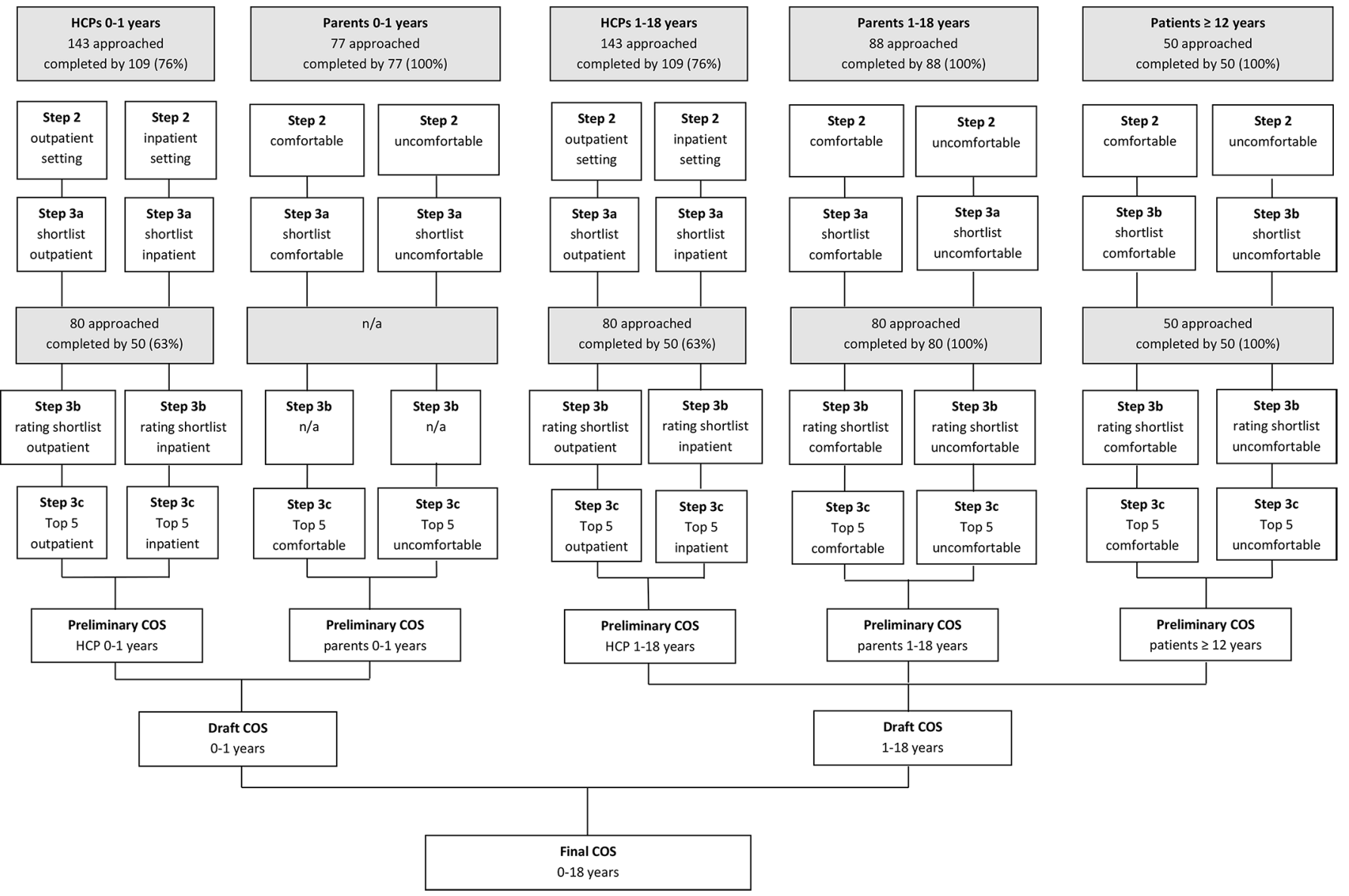

Figure 1 Flow diagram of the core outcome set (COS) development. HCPs, healthcare professionals; n/a, not applicable.

has shown that parents of children with FC have different concerns regarding their child's symptoms than HCPs. ${ }^{13}$

In recent years, several COS were developed for paediatric topics such as acute diarrhoea, infant colic and asthma. ${ }^{14-16}$ These studies used the Delphi technique to identify clinically important outcomes for HCPs and parents. Sinha et al also involved patients $\geq 12$ years in this process. ${ }^{16}$

This work was commissioned by the Consensus Group on Outcome Measures Made in Paediatric Enteral Nutrition Clinical Trials (COMMENT), an initiative of the European Society for Paediatric Gastroenterology Hepatology and Nutrition (ESPGHAN). COMMENT agreed that consensus was needed on core outcomes for FC. Therefore, we aim to develop a COS for therapeutic trials in children with FC, in primary to tertiary care settings.

\section{METHODS}

The method for the COS development was based on previous publications. ${ }^{14-16}$

The Medical Ethics Review Committee confirmed that the Medical Research Involving Human Subjects Act did not apply to this study and therefore official approval by the committee was not required.

Descriptive statistics were used to summarise results.
In step 1, we systematically assessed how definitions and outcomes were defined in therapeutic randomised controlled trials of children with FC. Results were published in two manuscripts; one concerning children $\leq 4$ years and another concerning children aged $1-18$ years. $^{217}$

\section{Table 1 Country of practice of participating HCPs}

\begin{tabular}{ll}
\hline Country of practice & No of HCPs \\
\hline Italy & 18 \\
Israel & 14 \\
UK & 10 \\
Poland & 9 \\
The Netherlands & 7 \\
Mexico/Turkey & 4 \\
Belgium/Ecuador/Germany/Greece & 3 \\
$\begin{array}{l}\text { Brazi/Czech Republic/New Zealand/ } \\
\text { Norway/Romania/Sweden/Thailand/USA }\end{array}$ & 2 \\
$\begin{array}{l}\text { Australia/Canada/Croatia/France/Japan/ } \\
\text { Jordan/Spain/Philippines/Russia }\end{array}$ & 1 \\
Not reported & 6 \\
Total & 109 \\
\hline
\end{tabular}

HCPs, healthcare professionals. 


\section{Participants}

In step 2, we collected important treatment outcomes among stakeholders.

A survey was conducted among HCPs visiting two international paediatric gastroenterology conferences. Participants were randomly approached and asked to list up to five harmful/beneficial treatment outcomes, which they considered important and guided their clinical decision-making in outpatient and inpatient settings, as outcomes could differ in these settings. Data regarding profession and country of practice were collected. We aimed to include $\geq 100$ HCPs. ${ }^{14}$

We aimed to include 160 parents in four countries (Belgium, Italy, Poland and the Netherlands). Parents of children with FC (according to the Rome III criteria) were randomly approached by their child's treating physician to participate in this anonymous survey. ${ }^{56}$ Parents were asked to list up to five treatment outcomes that made them feel comfortable or made them feel that their child was being treated adequately. The same question was asked for treatment outcomes that made parents feel uncomfortable or made them feel their child was being treated inadequately. Questions were translated into the native language of parents and answers were carefully translated back to English by their HCP.

As an anonymous pilot study, we assessed which treatment outcomes were relevant to patients $\geq 12$ years, diagnosed with FC according to the Rome III criteria. ${ }^{516}$

We aimed to include 50 patients at the gastroenterology outpatient clinic of the Emma Children's Hospital/ Academic Medical Centre, Amsterdam, the Netherlands. Children were randomly invited by their doctor and questions from the parental survey were adjusted for this population.

\section{Outcomes}

In step 3, reported outcomes were classified in predefined domains based on our findings in step 1 (defecation, associated symptoms, use of medication, treatment success, quality of life (QoL) and hospital). ${ }^{2}{ }^{17}$ Domains functioned as subcategories to group outcomes with similar characteristics. When necessary, we added new domains based on survey results. Similar outcomes were combined and outcomes mentioned by $\geq 10 \%$ of participants were included in a shortlist. The $10 \%$ threshold was chosen by COMMENT to keep shortlists manageable. Ten separate shortlists were created.

Next, shortlists for HCPs were sent to those that participated in the first survey and agreed to participate in the second survey as well. They were asked to rate outcomes on clinical relevance on a scale of $0-4(0=$ not relevant, $4=$ very relevant) and to prioritise outcomes by selecting five outcomes they thought to be most important in guiding their clinical decision-making.

A new group of parents and patients with FC, from the same four countries, was invited to participate in this phase. They received shortlists for parental and patient outcomes, respectively, and were asked to rank outcomes on a scale of $0-4(0=$ does not make me feel (un) comfortable, $4=$ makes me feel very (un)comfortable) and to prioritise them by selecting the five outcomes that made them feel most (un)comfortable. Surveys were returned anonymously. We aimed to include 80 parents and 50 patients. $^{1416}$

Subsequently, the five outcomes with the highest rank were selected for each group. This resulted in preliminary outcome sets for HCPs, parents and patients, for both age groups.

After combining the preliminary outcome sets for each age group, a draft COS was presented to an expert panel during the COMMENT Working Group (WG) meeting at the ESPGHAN meeting in Athens, Greece (2016). Here consensus (a unanimous decision) regarding the final COS was reached by discussion.

\section{RESULTS}

Flow diagram of COS development is shown in figure 1. One hundred and nine out of $143(76 \%)$ HCPs completed the first questionnaire. They originated from 28 countries (table 1) and included 52 paediatric gastroenterologists, 24 general paediatricians, 17 fellows, 4 residents in paediatrics, 4 paediatric nutritionists, 3 researchers, 3 not specified, 1 intern and 1 general doctor. In some originating countries, healthcare is organised in such a way that paediatricians represent primary and secondary care as well.

For infants aged $0-1$ years, 89 and 74 different outcomes were reported for outpatient and inpatient settings, respectively. For children aged 1-18 years, 76 and 72 different outcomes were reported for outpatient and inpatient settings, respectively. Table 2 shows an example of reported outcomes.

One hundred and sixty-five parents (100\%) of children with FC completed the first questionnaire. Parents of infants aged $0-1$ years reported 28 treatment outcomes that made them feel comfortable and 26 outcomes that made them feel uncomfortable. Parents of children aged 1-18 years reported 52 treatment outcomes that made them feel comfortable and 45 that made them feel uncomfortable.

Fifty patients $\geq 12$ years (mean age 14.8 years; response rate $100 \%$ ) completed the first questionnaire. Patients reported 21 outcomes that made them feel comfortable and 22 that made them feel uncomfortable.

Table 3 shows outcomes that were reported most frequently.

\section{Creating a shortlist and final COS}

Fifty out of 80 HCPs (63\%) completed the second questionnaire regarding the rating and prioritising of outcomes on the shortlist. Since the top 5 of outcomes for outpatient and inpatient settings were rather similar (tables 4 and 5), we combined these into one preliminary outcome set per age group. 
Table 2 Outcome measures as reported by healthcare professionals (HCPs) for the outpatient setting in children 1-18 years; step $2(n=109)$

\begin{tabular}{lll}
\hline Subdomain & Outcome & $\mathbf{n}$ \\
\hline Domain: defecation & & \\
Constipation & Duration of constipation & 3 \\
& Constipation & 2 \\
& Disappearance of constipation & 2 \\
\hline Defecation frequency & Defecation frequency & 60 \\
& Regular soft bowel movements & 1 \\
Stool consistency & Stool consistency & 34 \\
Painful defecation & Quality of stools & 3 \\
\hline
\end{tabular}

\section{Domain: associated symptoms}

\begin{tabular}{|c|c|c|}
\hline \multirow[t]{4}{*}{ Abdominal pain/discomfort } & Abdominal pain & 42 \\
\hline & Discomfort & 14 \\
\hline & No bowel distention & 1 \\
\hline & Abdominal bloating & 1 \\
\hline Faecal incontinence & Faecal incontinence & 28 \\
\hline \multirow[t]{9}{*}{ Bowel habits - other } & Blood in stool & 9 \\
\hline & Less anxious to defecate & 3 \\
\hline & Normal bowel movement & 2 \\
\hline & Less stool withholding & 2 \\
\hline & Clarity of bowel movement & 1 \\
\hline & Amount of stool & 1 \\
\hline & Sensation of emptying & 1 \\
\hline & Number of days without stool & 1 \\
\hline & Emergency defecation on the way to school & 1 \\
\hline Crying & Crying & 4 \\
\hline Straining & Straining & 3 \\
\hline Other gastrointestinal complaints & Less gas & 1 \\
\hline \multicolumn{3}{|l|}{ Domain: quality of life } \\
\hline \multirow[t]{6}{*}{ Quality of life } & Quality of life of child/parents & 18 \\
\hline & Reduce stress in family & 4 \\
\hline & Reduce parental anxiety & 3 \\
\hline & Behaviour/energy/mood of child & 3 \\
\hline & Normal social life & 1 \\
\hline & Parent's discomfort & 1 \\
\hline \multicolumn{3}{|l|}{ Domain: treatment success } \\
\hline \multirow[t]{4}{*}{ Faecal impaction } & Rectal impaction & 3 \\
\hline & Faecal impaction resolves & 1 \\
\hline & Efficiency of disimpaction & 1 \\
\hline & No effect of clean out & 1 \\
\hline \multirow[t]{3}{*}{ Satisfaction } & Satisfaction of child/parent & 4 \\
\hline & Patient satisfaction & 1 \\
\hline & Parental satisfaction & 1 \\
\hline Treatment compliance & Treatment compliance & 5 \\
\hline
\end{tabular}


Table 2 Continued

\begin{tabular}{|c|c|c|}
\hline Subdomain & Outcome & $\mathbf{n}$ \\
\hline \multirow[t]{6}{*}{ Diet } & Diet & 3 \\
\hline & Improve appetite/normalisation of food intake & 3 \\
\hline & Eating problems & 2 \\
\hline & Less milk & 1 \\
\hline & More fibre & 1 \\
\hline & Nutritional status & 1 \\
\hline \multirow[t]{5}{*}{ Education } & Parental reassurance & 1 \\
\hline & Explanation of normal stool pattern & 1 \\
\hline & Explanation of long duration of therapy & 1 \\
\hline & Re-education & 1 \\
\hline & Explanation about the disease & 1 \\
\hline \multirow[t]{2}{*}{ Improvement } & Time to improvement of symptoms & 2 \\
\hline & Improvement of clinical status & 1 \\
\hline Adequate relief & Adequate relief rated by patients and parents & 1 \\
\hline Lack of success & Lack of success & 1 \\
\hline \multicolumn{3}{|c|}{ Domain: use of medication } \\
\hline \multirow[t]{7}{*}{ Medication } & Use of laxatives & 8 \\
\hline & Characteristics of medication (like taste and side effects) & 8 \\
\hline & Re-education of pharmacological treatment & 2 \\
\hline & No medication required & 2 \\
\hline & Efficacy of medication & 2 \\
\hline & Decrease of harmful medication & 1 \\
\hline & Already used medication & 1 \\
\hline \multicolumn{3}{|l|}{ Domain: hospital } \\
\hline \multirow[t]{2}{*}{ Hospital visits } & Fewer consultations with HCPs & 3 \\
\hline & Number of visits to outpatient department & 1 \\
\hline \multicolumn{3}{|l|}{ Domain: other } \\
\hline \multirow[t]{2}{*}{ Growth } & Thriving/growth & 5 \\
\hline & Weight loss & 1 \\
\hline \multirow[t]{11}{*}{ Other } & School attendance & 4 \\
\hline & Manage anal fissure & 3 \\
\hline & Sleep & 2 \\
\hline & Frequency of voiding & 1 \\
\hline & Costs of treatment & 1 \\
\hline & Presence of alarm symptoms & 1 \\
\hline & Adequate nursing by family & 1 \\
\hline & Physical examination & 1 \\
\hline & Colonic transit time & 1 \\
\hline & Decrease of diameter of the rectum & 1 \\
\hline & Control of sphincter & 1 \\
\hline
\end{tabular}

Three unclear outcomes such as 'familiar environment' and 'organisation' were not displayed.

In step 2, only five outcomes were mentioned by $>10 \%$ of the parents of infants $0-1$ years. It was unnecessary to approach new parents for step 3, as the rating and prioritising would not affect the top 5 outcomes.
All 80 parents of children $1-18$ years $(100 \%)$ completed step 3 . Tables 4 and 5 show the shortlists that were rated and prioritised by parents. Since outcomes that made parents feel comfortable and uncomfortable were rather 


\begin{tabular}{|c|c|c|}
\hline \multicolumn{3}{|c|}{ Infants $0-1$ years } \\
\hline \multirow[t]{4}{*}{ HCP } & Outpatient setting & Inpatient setting \\
\hline & $\begin{array}{l}\text { Defecation frequency } \\
(51 \%)\end{array}$ & $\begin{array}{l}\text { Defecation frequency } \\
(46 \%)\end{array}$ \\
\hline & Abdominal pain (32\%) & $\begin{array}{l}\text { Stool consistency } \\
(28 \%)\end{array}$ \\
\hline & Stool consistency (30\%) & Abdominal pain (20\%) \\
\hline \multirow[t]{4}{*}{ Parents } & Comfortable & Uncomfortable \\
\hline & Stool consistency (39\%) & $\begin{array}{l}\text { Stool consistency } \\
(56 \%)\end{array}$ \\
\hline & $\begin{array}{l}\text { Defecation frequency } \\
(38 \%)\end{array}$ & Straining (38\%) \\
\hline & Crying (17\%) & $\begin{array}{l}\text { Defecation frequency } \\
(34 \%)\end{array}$ \\
\hline
\end{tabular}

\section{Children 1-18years}

\begin{tabular}{|c|c|c|}
\hline \multirow[t]{4}{*}{ HCP } & Outpatient & Inpatient \\
\hline & $\begin{array}{l}\text { Defecation frequency } \\
(55 \%)\end{array}$ & $\begin{array}{l}\text { Defecation frequency } \\
(46 \%)\end{array}$ \\
\hline & Abdominal pain (39\%) & Abdominal pain (27\%) \\
\hline & Stool consistency $(30 \%)$ & $\begin{array}{l}\text { Stool consistency } \\
(26 \%)\end{array}$ \\
\hline \multirow[t]{4}{*}{ Parents } & Comfortable & Uncomfortable \\
\hline & $\begin{array}{l}\text { Defecation frequency } \\
(41 \%)\end{array}$ & Abdominal pain (40\%) \\
\hline & Abdominal pain (39\%) & $\begin{array}{l}\text { Faecal incontinence } \\
(25 \%)\end{array}$ \\
\hline & Stool consistency (25\%) & $\begin{array}{l}\text { Defecation frequency } \\
(25 \%)\end{array}$ \\
\hline \multirow[t]{4}{*}{ Patients } & Comfortable & Uncomfortable \\
\hline & Abdominal pain (66\%) & Abdominal pain (58\%) \\
\hline & $\begin{array}{l}\text { Defecation frequency } \\
(40 \%)\end{array}$ & $\begin{array}{l}\text { Defecation frequency } \\
(35 \%)\end{array}$ \\
\hline & $\begin{array}{l}\text { Faecal incontinence } \\
(32 \%)\end{array}$ & $\begin{array}{l}\text { Faecal incontinence } \\
(28 \%)\end{array}$ \\
\hline
\end{tabular}

HCP, healthcare professional.

similar for this age group, we combined these into one preliminary outcome set.

Fifty patients (mean age 13.8 years; response rate $100 \%$ ) completed the rating and prioritising of outcomes (table 6). Outcomes that made patients feel comfortable and uncomfortable were rather similar and we combined these into one preliminary outcome set.

The preliminary COS of HCPs and parents of infants $0-1$ years old were comparable. Therefore, these were combined into the following draft COS: defecation frequency, stool consistency, painful defecation, discomfort, crying, abdominal pain, treatment success, straining and QoL of parents.

We repeated this process for children 1-18 years but added the outcomes mentioned by patients aged $\geq 12$ years. The preliminary COS of HCPs, parents and patients appeared to be comparable as well, except for the following outcomes: 'abdominal pain' (mentioned by parents and patients), 'treatment success' (parents) and 'school attendance' (patients). We combined outcomes into the following draft COS: defecation frequency, stool consistency, painful defecation, QoL (child and parents), faecal incontinence, abdominal pain, school attendance and treatment success.

The draft COS for both age groups was presented in a COMMENT WG meeting. Regarding the COS for $0-1$ years, it was unanimously decided to exclude 'discomfort', 'abdominal pain' and 'crying' in the final COS, since these outcomes are non-specific and cannot with certainty be attributed to FC or the treatment effect. Additionally, it was decided to exclude 'straining', since 'painful defecation' was already included in the COS. 'Treatment success' was excluded as it is assumed to be a combination of the included outcomes.

Regarding the COS for 1-18 years, it was unanimously decided to add two outcomes mentioned by parents/ patients: 'abdominal pain' and 'school attendance'. 'Treatment success' was excluded for the same reason as above.

Since the applicability of a treatment depends on a balance between benefits and side effects of that treatment, it is recommended to assess 'side effects' as part of the COS. ${ }^{18}$ Although 'side effects of treatment' were mentioned by $<10 \%$ of respondents, we added this outcome to the COS. The COS for infants $0-1$ years therefore includes: defecation frequency, stool consistency, painful defecation, QoL of the parents and side effects of treatment. The COS for children 1-18 years includes: defecation frequency, stool consistency, painful defecation, QoL of patients and parents, faecal incontinence, abdominal pain, school attendance and side effects of treatment.

For practical reasons, we combined these into one final COS for all children aged $0-18$ years (box 1 ).

\section{DISCUSSION}

HCPs, parents and patients $\geq 12$ years were involved in a Delphi technique to develop a COS for children with FC aged $0-18$ years. Stakeholders largely agreed on which outcomes were most important, but some discrepancies existed. Parents and patients found 'abdominal pain' more important than HCPs. Although it is not a characteristic feature of $\mathrm{FC}, 10 \%-70 \%$ of children with $\mathrm{FC}$ are suffering from abdominal pain which can have a large impact on their well-being. ${ }^{19}$ Abdominal pain can lead to school absenteeism and reduce participation in social activities. Another discrepancy regarded 'defecation frequency': depending on the age group, $46 \%-55 \%$ of HCPs found this the most important treatment outcome, whereas parents and patients mentioned this less often as an important outcome.

Interestingly, most Rome IV criteria are represented in our COS, except for "presence of a large faecal mass 
Table 4 Shortlist outcome measures (rated and prioritised) for infants $0-1$ years old

\begin{tabular}{|c|c|c|c|c|}
\hline Rank & Outcome measures & Domain & Percentage & Average rating \\
\hline \multicolumn{5}{|c|}{ Healthcare professionals } \\
\hline \multicolumn{5}{|c|}{ Outpatient setting } \\
\hline 1 & Defecation frequency & Defecation & 96 & 3.14 \\
\hline 2 & Painful defecation & Defecation & 94 & 2.98 \\
\hline 3 & Stool consistency & Defecation & 82 & 3.20 \\
\hline 4 & Discomfort & Associated symptoms & 74 & 2.28 \\
\hline 5 & Quality of life (parents) & Quality of life & 64 & 1.76 \\
\hline 6 & Abdominal pain & Associated symptoms & 36 & 1.44 \\
\hline 7 & Crying & Associated symptoms & 36 & 0.18 \\
\hline 8 & Faecal incontinence & Associated symptoms & 18 & 0.76 \\
\hline \multicolumn{5}{|c|}{ Inpatient setting } \\
\hline 1 & Defecation frequency & Defecation & 92 & 3.18 \\
\hline 2 & Stool consistency & Defecation & 88 & 3.24 \\
\hline 3 & Painful defecation & Defecation & 84 & 2.94 \\
\hline 4 & Discomfort & Associated symptoms & 72 & 2.30 \\
\hline 5 & Quality of life (parents) & Quality of life & 62 & 2.31 \\
\hline 6 & Time of hospitalisation & Hospital & 52 & 1.82 \\
\hline 7 & Abdominal pain & Associated symptoms & 28 & 1.50 \\
\hline 8 & Faecal incontinence & Associated symptoms & 22 & 0.80 \\
\hline
\end{tabular}

\section{Parents}

\section{Comfortable}

$\begin{array}{llll}1 & \text { Stool consistency } & \text { Defecation } & \text { N/A N/A } \\ 2 & \text { Defecation frequency } & \text { Defecation } & \\ 3 & \text { Crying } & \text { Associated symptoms } & \\ 4 & \text { Abdominal pain } & \text { Associated symptoms } & \\ 5 & \text { Treatment success } & \text { Treatment success } & \\ \text { Uncomfortable } & & & \text { N/A } \\ 1 & \text { Stool consistency } & \text { Defecation } & \text { N/A } \\ 2 & \text { Straining } & \text { Associated symptoms } & \\ 3 & \text { Defecation frequency } & \text { Defecation } & \\ 4 & \text { Crying } & \text { Associated symptoms } & \\ 5 & \text { Painful defecation } & \text { Defecation } & \end{array}$

N/A, not applicable.

Outcomes ranked 1 to 5 no background colour and outcomes ranked 6 to 8 (if applicable a darker colour to visualise they were excluded from the top 5 .

in the rectum', 'retentive posturing' and 'large diameter stools' which were mentioned by $3 \%, 2 \%$ and $0 \%$ of HCPs, respectively. Furthermore, 'faecal incontinence' was mentioned as an important outcome for infants aged 0-1 years. A potential explanation for this could be that this was a Rome III criterion for children aged 0-4 years. Since this is very difficult to assess in children wearing diapers, the Rome IV criterion 'faecal incontinence' is only used as an additional criterion to diagnose FC in toilet-trained children. ${ }^{8}$

One of the strengths of this study is the high response rate. Furthermore, participation of physicians around the globe, involvement of parents from four European countries and inclusion of patients increase the generalisability of our COS. This study has some limitations. First, our study focused on children whose FC is managed by hospital paediatricians. In some participating countries, however, healthcare is organised in such a manner that paediatricians represent primary and secondary care as well. Although we included participants from around the globe, developing countries were under-represented which may limit the external validity of this COS in a developing country setting. Data collection from HCPs occurred at international paediatric gastroenterology 
Table 5 Shortlist outcome measures (rated and prioritised) for children 1-18 years old

\begin{tabular}{|c|c|c|c|c|}
\hline Rank & Outcome measures & Domain & Percentage & Average rating \\
\hline \multicolumn{5}{|c|}{ Healthcare professionals } \\
\hline \multicolumn{5}{|c|}{ Outpatient setting } \\
\hline 1 & Faecal incontinence & Associated symptoms & 94 & 3.63 \\
\hline 2 & Defecation frequency & Defecation & 84 & 3.50 \\
\hline 3 & Painful defecation & Defecation & 78 & 3.24 \\
\hline 4 & Stool consistency & Defecation & 78 & 3.16 \\
\hline 5 & Quality of life (child/parents) & Quality of life & 76 & 3.31 \\
\hline 6 & Abdominal pain & Associated symptoms & 66 & 2.60 \\
\hline 7 & Discomfort & Associated symptoms & 24 & 1.76 \\
\hline \multicolumn{5}{|c|}{ Inpatient setting } \\
\hline 1 & Faecal incontinence & Associated symptoms & 88 & 3.59 \\
\hline 2 & Defecation frequency & Defecation & 86 & 3.48 \\
\hline 3 & Stool consistency & Defecation & 78 & 3.24 \\
\hline 4 & Painful defecation & Defecation & 74 & 3.18 \\
\hline 5 & Quality of life (child/parents) & Quality of life & 70 & 2.98 \\
\hline 6 & Abdominal pain & Associated symptoms & 52 & 2.54 \\
\hline 7 & Time of hospitalisation & Hospital & 40 & 2.28 \\
\hline 8 & Discomfort & Associated symptoms & 12 & 1.72 \\
\hline
\end{tabular}

Parents

\begin{tabular}{|c|c|c|c|c|}
\hline \multicolumn{5}{|c|}{ Comfortable } \\
\hline 1 & Quality of life (child and parents) & Quality of life & 83 & 3.41 \\
\hline 2 & Abdominal pain & Associated symptoms & 77 & 3.30 \\
\hline 4 & Painful defecation & Defecation & 66 & 2.96 \\
\hline 5 & Stool consistency & Defecation & 65 & 3.16 \\
\hline 8 & Complete information given by doctor & Other & 36 & 2.81 \\
\hline \multicolumn{5}{|c|}{ Uncomfortable } \\
\hline 1 & Lack of treatment success & Treatment success & 88 & 2.40 \\
\hline 2 & Abdominal pain & Associated symptoms & 84 & 2.95 \\
\hline 6 & Lack of information given by doctor & Other & 44 & 1.92 \\
\hline
\end{tabular}

Outcomes ranked 1 to 5 no background colour and outcomes ranked 6 to 8 (if applicable a darker colour to visualise they were excluded from the top 5 .

conferences. This may have caused bias since these HCPs often treat patients with severe and long-lasting FC, and they could therefore have chosen different outcomes compared with primary care physicians. Also, patients $\geq 12$ years were recruited in a tertiary care setting as a pilot study. Only recruiting patients in such a specialised setting might have led to biased results.

Furthermore, since answers were collected anonymously in both Delphi rounds, we were unable to assess any potential differences between respondents and non-respondents. The Delphi technique is well suited as a method for consensus building, but it is a time-consuming process, that requires active participation throughout the Delphi process, which can result in high dropout rates. ${ }^{20}$ However, our response rates were $63 \%-100 \%$ in both steps.

Another potential limitation is the use of questionnaires that were developed in English and thereafter translated into 


\begin{tabular}{|c|c|c|c|c|}
\hline Rank & Outcome measures & Domain & Percentage & Average rating \\
\hline \multicolumn{5}{|c|}{ Comfortable } \\
\hline 1 & Abdominal pain & Associated symptoms & 86 & 3.52 \\
\hline 2 & School absence & Treatment success & 74 & 3.14 \\
\hline 3 & Faecal incontinence & Associated symptoms & 66 & 2.86 \\
\hline 4 & Quality of life (child) & Quality of life & 54 & 2.94 \\
\hline 5 & Defecation frequency & Defecation & 52 & 2.58 \\
\hline 6 & Stool consistency & Defecation & 42 & 2.46 \\
\hline 7 & Use of medication & Use of medication & 16 & 1.92 \\
\hline \multicolumn{5}{|c|}{ Uncomfortable } \\
\hline 1 & Abdominal pain & Associated symptoms & 86 & 3.38 \\
\hline 2 & School absence & Treatment success & 70 & 3.08 \\
\hline 3 & Faecal incontinence & Associated symptoms & 68 & 3.06 \\
\hline 4 & Quality of life (child) & Quality of life & 50 & 2.74 \\
\hline 5 & Defecation frequency & Defecation & 48 & 2.48 \\
\hline 6 & Stool consistency & Defecation & 40 & 2.42 \\
\hline 7 & Use of medication & Use of medication & 22 & 2.18 \\
\hline
\end{tabular}

Outcomes ranked 1 to 5 no background colour and outcomes ranked 6 to 8 (if applicable a darker colour to visualise they were excluded from the top 5 .

Box 1 Final core outcome set for functional constipation in children $\mathbf{0 - 1 8}$ years
Defecation frequency
- Stool consistency
Painful defecation
Quality of life of parents and patients
- Side effects of treatment
- Faecal incontinence, if age appropriate
Abdominal pain, if age appropriate
School attendance, if age appropriate

four different languages. Although this was done carefully, it is possible that this resulted in subtle changes in questions or answers. Some responses in step 2 were somewhat open to interpretation; therefore, we may have misinterpreted and incorrectly combined outcomes. Furthermore, not all outcomes mentioned by parents or patients were included in the final COS. The WG unanimously decided that these outcomes were non-specific for FC (crying, discomfort) or already included in the COS (straining, treatment success).

As mentioned before, a COS is the basis for what should be measured and reported in clinical trials, but researchers can add more outcomes if needed. ${ }^{21}$ Selective reporting should be avoided by presenting results for both core outcomes and additional outcomes.

To enable comparison of trial results, there is not only a need for consensus regarding outcomes, we also need homogeneity in used definitions of FC. We recommend to use the recently published and internationally accepted Rome IV criteria for FC in future trials. $^{7}$

COS have the potential to improve evidence-based healthcare, but their creation does not automatically lead to its implementation and it would therefore be valuable to assess how widely this COS is being implemented.

In conclusion, the COS for childhood FC (0-18 years) consists of defecation frequency, stool consistency, painful defecation, QoL and side effects. Faecal incontinence, abdominal pain and school attendance should be measured if age appropriate. We recommend researchers to use this COS to decrease outcome heterogeneity and improve comparability of study results.

Acknowledgements We thank all HCPs, parents and patients who completed the questionnaires, and JJ Korterink, MH Vriesman and K Wojtyniak for their help with the recruitment.

Contributors SK-W: participated in the design of the study, collected data, performed data analyses, drafted the initial manuscript and approved the final manuscript as submitted. NFS: participated in the design of the study, collected data, performed data analyses, drafted the initial manuscript and approved the final manuscript as submitted. MAB: participated in the design of the study, supervised drafting of the manuscript and approved the final manuscript as submitted. TD: collected data, participated in writing the manuscript and approved the final manuscript as submitted. ES: collected data, participated in writing the manuscript and approved the final manuscript as submitted. AS: participated in the design of the study, collected data and approved the final manuscript as submitted. YV: participated in the design of the study, collected data and approved the final manuscript as submitted. HS: participated in the design of the study, collected data and approved the final manuscript as submitted. MMT: participated in the design of the study, supervised drafting of the manuscript and approved the final manuscript as submitted. 
Competing interests None declared.

Patient consent Obtained.

Provenance and peer review Commissioned; externally peer reviewed.

Data sharing statement Tables with reported outcome measures of step 2 are available from the authors.

Open Access This is an Open Access article distributed in accordance with the Creative Commons Attribution Non Commercial (CC BY-NC 4.0) license, which permits others to distribute, remix, adapt, build upon this work non-commercially, and license their derivative works on different terms, provided the original work is properly cited and the use is non-commercial. See: http://creativecommons.org/ licenses/by-nc/4.0/

(C) Article author(s) (or their employer(s) unless otherwise stated in the text of the article) 2017. All rights reserved. No commercial use is permitted unless otherwise expressly granted.

\section{REFERENCES}

1 Mugie SM, Benninga MA, Di Lorenzo C. Epidemiology of constipation in children and adults: a systematic review. Best Pract Res Clin Gastroenterol 2011;25:3-18.

2 Kuizenga-Wessel S, Benninga MA, Tabbers MM. Reporting outcome measures of functional constipation in children from 0 to 4 years of age. J Pediatr Gastroenterol Nutr 2015;60:446-56.

3 Baker SS, Liptak GS, Colletti RB, et al. Constipation in infants and children: evaluation and treatment. A medical position statement of the North American Society for Pediatric Gastroenterology and Nutrition. J Pediatr Gastroenterol Nutr 1999;29:612-26.

4 Boccia G, Manguso F, Coccorullo P, et al. Functional defecation disorders in children: PACCT criteria versus Rome II criteria. J Pediatr 2007:151:e1:394-98.

5 Rasquin A, Di Lorenzo C, Forbes D, et al. Childhood functional gastrointestinal disorders: child/adolescent. Gastroenterology 2006;130:1527-37.

6 Hyman PE, Milla PJ, Benninga MA, et al. Childhood functional gastrointestinal disorders: neonate/toddler. Gastroenterology 2006;130:1519-26.

7 Hyams JS, Di Lorenzo C, Saps M, et al. Functional disorders: children and adolescents. Gastroenterology 2016:S00165085(16)00181-5.
8 Benninga MA, Faure C, Hyman PE, et al. Childhood functional gastrointestinal disorders: neonate/toddler. Gastroenterology 2016:1443-55

9 Benstoem C, Moza A, Autschbach R, et al. Evaluating outcomes used in cardiothoracic surgery interventional research: a systematic review of reviews to develop a core outcome set. PLoS One 2015;10:e0122204.

10 Wuytack F, Smith V, Clarke M, et al. Towards core outcome set (COS) development: a follow-up descriptive survey of outcomes in Cochrane reviews. Syst Rev 2015;4:73.

11 Gargon E, Williamson PR, Clarke M. Collating the knowledge base for core outcome set development: developing and appraising the search strategy for a systematic review. BMC Med Res Methodol 2015;15:26.

12 Clarke M, Williamson PR. Core outcome sets and systematic reviews. Syst Rev 2016;5:11.

13 Farrell M, Holmes G, Coldicutt P, et al. Management of childhood constipation: parents' experiences. J Adv Nurs 2003;44:479-89.

14 Karas J, Ashkenazi S, Guarino A, et al. . A core outcome set for clinical trials in acute diarrhoea. Arch Dis Child 2015;100:359-63.

15 Steutel NF, Benninga MA, Langendam MW, et al. Reporting outcome measures in trials of infant colic. J Pediatr Gastroenterol Nutr 2014;59:341-6.

16 Sinha IP, Gallagher R, Williamson PR, et al. Development of a core outcome set for clinical trials in childhood asthma: a survey of clinicians, parents, and young people. Trials 2012;13:103

17 Kuizenga-Wessel S, Heckert SL, Tros W, et al. Reporting on outcome measures of functional constipation in children: a systematic review. $J$ Pediatr Gastroenterol Nutr 2016:62:840-6.

18 Boers M, Kirwan JR, Wells G, et al. Developing core outcome measurement sets for clinical trials: OMERACT filter 2.0. J Clin Epidemiol 2014;67:745-53.

19 Bharucha AE, Wald A, Enck P, et al. Functional anorectal disorders Gastroenterology 2006;130:1510-8.

20 Keeney S, Hasson F, McKenna HP. A critical review of the Delphi technique as a research methodology for nursing. Int J Nurs Stud 2001;38:195-200.

21 Kilic L, Erden A, Bingham CO, et al. The reporting of patient-reported outcomes in studies of patients with rheumatoid arthritis: a systematic review of 250 articles. J Rheumatol 2016;43:1300-5. 